\title{
Open access in humanities and social sciences
}

Visions for the future of publishing

$\mathbf{F}_{8}^{\circ}$ or this month's column, the editors are gearing up for the Library Publishing Forum, which will be held March 29-30, 2015, at Portland State University in Portland, Oregon. We have interviewed the forum's keynote speakers, Martin Paul Eve and John Willinsky, who will share their vision of open access in the humanities and social sciences as well as their thoughts on future developments.

\section{Interview with Martin Paul Eve on open access in the humanities}

\section{Please tell readers about yourself in a couple of sentences. \\ I am a lecturer (equivalent of your tenured professor) in English at the University of Lincoln, United Kingdom. I have written two books, one on the novelist Thomas Pynchon ${ }^{1}$ and the other, probably more relevant for the constituency here, on open access and the humanities (itself available open access). ${ }^{2}$ I am also a founder and director of the Mellon-funded Open Library of Humanities (OLH) project. ${ }^{3}$}

2. What is your vision of open access publishing for the humanities? What will it take for the academic community to accomplish it?

Beyond fixing the access crisis and achieving a better integration of the humanities with broader society, my vision for open access in the humanities is best summed up in the philosophy of OLH: cooperation. Much of our practice in the contemporary university is predicated on competition. We compete for students, for grant funds, and for faculty, among other areas. We know, though, that in the publishing world, the system of markets and competition has failed us. This is because it is not really a market: there is no substitute product for a book or article when a researcher needs it. There is, though, a great deal of competition among academics to publish in high-prestige venues, which means these often-commercial entities have a high level of market power. This has led to the extreme hyperinflationary cost increases in the serials market that we've seen since 1986 .

The academy, though, is very conservative. To change the social elements of academic practice can take 20 years or more. Academics will not, overnight, submit to new journals and new publishers unless the underlying incentives (usually financial for their institutions and their own careers, medi-

Martin Paul Eve is lecturer at the University of Lincoln, email:meve@lincoln.ac.uk, and JohnWillinsky is professor at Stanford University, email: john.willinsky@stanford.edu

Contact series editors Zach Coble, digital scholarship specialist at New York University, and Adrian Ho, director of digital scholarship at the University of Kentucky Libraries, at crlnscholcomm@gmail.com with article ideas

๑) 2015 Martin Paul Eve and John Willinsky 
ated through prestige) also change. In some countries with centralized funding, such as the United Kingdom, this is easier. In others, such as the United States, it is far harder. This means that, even if we did manage to get universal green $\mathrm{OA}$ or switch to an article processing charge (APC)-driven version of gold OA, we would still face the same market dysfunction, even if we did achieve OA.

What we propose to do, instead, is build a library consortium to underwrite the labor of publishing on a not-for-profit basis, offering societies an opportunity to do gold OA without author-facing charges. In this way, we can facilitate collaboration and cooperation between libraries, while deferring the larger problems of academic practice. We also have a clear route to transition where libraries should actually see real cancellations: as existing journals can come on board our system, with existing academic author-bases, we do OA "by stealth," converting existing journals to APC-free gold OA. In this way, there is no need for academics to do anything different, but we can fix the access crisis.

\section{What issue(s) about open access} publishing in the humanities do you think warrants immediate attention and action?

Two issues immediately spring to mind: providing education where there are misconceptions and addressing the economic challenges where they are real. For the former, it is interesting that many in the humanities still think that all OA must be APC-driven gold, that it must be lower quality (or completely divorced from peer review), and that OA will facilitate plagiarism. This can only be countered by persistent denials and counter-examples.

At the same time, though, it is crucial that we develop alternative models to fund gold OA for these disciplines. In the humanities, most research work does not come with external funding for dissemination. This makes the threat of APCs (which act to shift the entire burden onto a single institution, as opposed to subscriptions, which spread the risk) more pressing in these subject areas. Again, I point to our OLH project, but also to $\operatorname{arXiv}^{4}$ and Knowledge Unlatched, as examples of how we can remunerate the labor of publishing but in such a way that we share the costs between institutions and work together to make OA possible in the economic climate of these disciplines.

The other challenge for the humanities disciplines lies in monographs. These publications have different sites of reception and altered economic cycles compared with journals. They are expected to appear in book shops, which depends upon gatekept aggregation systems and also means that value is expected to come at a price, rather than for free online. Thus, it is a mistake to simply treat them as scaled-up articles. For instance, the trade-crossover market of these publications can be seen as either an opportunity or a challenge. It is an opportunity because it presents another route by which the cost of the labor of publishing might be covered. It is a challenge, though, because in this environment, print must always continue to exist and the costs of marketing, etc. remain. That said, there are many projects already investigating these problems such as OAPEN-NL, ${ }^{6}$ OAPEN-UK, ${ }^{7}$ the HEFCE Monographs project, ${ }^{8}$ and various Mellon-funded projects in the United States.

\section{What recommendations do you have for university presses and aca- demic/research libraries to further the development of open access in the hu- manities?}

University presses and libraries need to work together to sell the message of OA to researchers. This has to be a combined focus on the unsustainability of the current system for all participants and, more positively, on the broader reach and engagement that can be fostered by OA. This outreach is tiring and takes a lot of effort. But unless the efforts continue, researchers will not see the problem or understand the benefits, and the opportunity of this potentially historic moment will be lost. 


\section{Interview with John Willinsky on open access in the social sciences}

\section{Please tell readers about yourself in a couple of sentences.}

I was originally a schoolteacher by trade and am now a professor in Stanford University's Graduate School of Education. I also continue to work with Simon Fraser University Library on the Public Knowledge Project (PKP), ${ }^{9}$ and as a part-time professor in the university's Publishing Studies Program. I started PKP in 1998 to make open source scholarly publishing platforms for journals, monographs, and conferences. These systems, which we continue to update and distribute for free, are being actively used. For example, Open Journal Systems ${ }^{10}$ is used by some 7,000 largely open access journals worldwide today. I have always felt it important to find ways to help others use new technologies to engage more in a global exchange of knowledge.

\section{What is your vision of open access publishing for the social sciences? What will it take for the academic community to accomplish it?}

To begin, I should state simply that my vision is for open access in the social sciences. This is the area of my own research training. It is a broad field of inquiry having to do with the human situation and, as such, it strikes me that all of humankind has a right to this research and scholarship conducted in the interest of the greater good of humankind. A further part of my vision is that open access will increase the contributions that the social sciences make to social policies and professional practice in areas such as education. More generally, open access to this knowledge can only increase the democratic and educational qualities of people's lives, which is what inspired me to start my career as a schoolteacher in Northern Ontario.

Now to a certain, if not amazing, extent, this vision of open access has been realized by a great many social science journal editors who have started open access journals on the strength of their commitment to making this knowledge public. These editors have demonstrated time and again over the last two decades that the highest-quality peerreviewed journals can be run at very low expense on the basis of their and others' hard work. However, the overall proportion of the literature that is open access is still very much in the minority.

What is needed, now that we have demonstrated an interest in open access among editors, readers, researchers, and libraries, as well as publishers and funding agencies, is a new model for wide-scale adoption. At this point, APFs are bringing the big publishers on board with open access, but I think it is clear to most everyone that this model will not work across the disciplines or on a global basis. The APFs set by the big publishers, whether profit or nonprofit, often run up to an unaffordable level, although some are more reasonably priced. The answer is not to calibrate the APF to the discipline's funding base, as if the game is to get as much as you can per article. The social sciences need to lead the way in testing models that will apply to all disciplines and create greater equality of access, and professionalism, to publishing.

Among the ideas being tested, I'm currently supporting the idea of publisher-library cooperatives forming among groups of open access journals and libraries to provide professional publishing support based on converting subscription fees to paying for publishing costs. Martin Eve and Caroline Edward at the Open Library of Humanities are currently exploring such a model under the title Library Partnership Subsidies. ${ }^{11}$ Similarly, my work with a group of anthropology journal editors, led by Alberto Jiminez, is to test the forming of a journal-library collective. I see much to be gained by journals' editorial teams and societies through partnering with libraries. They will benefit from the libraries' involvement in hosting and information science support. It will take much experimentation to scale this model up. The goal is to have the entire research library community redirecting its subscription fees 
budget to underwriting the actual publishing costs across the disciplines, without the huge discrepancies and price increases that plague the current market and keep research out of the public's hands.

\section{What issue(s) about open access} publishing in the social sciences do you think warrants immediate attention and action?

One issue I would identify is the role of the social science scholarly societies in open access. The societies now have to consider to what degree the journals must remain profit centers for running the society. They need to explore open access models that will better serve their membership and readers, including the larger community. Let us have that open discussion about what is the appropriate economic model for scholarly communication and the society's vital role in it.

4. What recommendations do you have for university presses and academic/research libraries to further the development of open access in the social sciences?

Following what I have written above, I can only recommend that presses and libraries explore alternative models of cooperative and collective action based on covering rigorously academic and professionally managed publishing costs. I have worked for well over a decade, and will continue to work with the dedicated team at PKP to provide one piece

\section{"Recruiting ..." (cont. from page 78)}

\section{Notes}

1. E. Lombard, "The role of the academic library in college choice," Journal of Academic Librarianship 38 (4):237-41.

2. K. M. Soria, "Factors predicting the importance of libraries and research activities for undergraduates," Journal of Academic Librarianship 39 (6):464-70.

3. M. D. Behr, M. Bundza, and B. J. Cockrell, "Going for the gold: Recruiting students and engaging administrators through education and entertainment in the library," College of this puzzle by producing the most technically sophisticated and elegant management and publishing platform we can. And we're not the only ones out there doing this. How strange it is to put free-market competitive pricing of publishing services at the forefront of a cooperative and universal model of open access to research and scholarship. We live in strange and interesting times for learning, with the potential, surely, for great things.

\section{Notes}

1. Pynchon and Philosophy (London: Palgrave Macmillan, 2014).

2. Open Access and the Humanities: http:// dx.doi.org/10.1017/CBO9781316161012.

3. Open Library of Humanities: https:// www.openlibhums.org.

4. arXiv: http://arxiv.org/.

5. Knowledge Unlatched: http://www. knowledgeunlatched.org/.

6. OAPEN-NL: http://www.oapen.nl /index.php?option $=$ com_content $\&$ view $=$ article $\&$ id $=58 \&$ Itemid $=63$.

7. OAPEN-UK: http://oapen-uk.jiscebooks.org/.

8. HEFCE Monographs project: http:// www.hefce.ac.uk/whatwedo/rsrch /rinfrastruct/oa/monographs/.

9. Public Knowledge Project: https://pkp. sfu.ca/.

10. Open Journal Systems: https://pkp. sfu.ca/ojs/.

11. Library Partnership Subsidies: https://www.openlibhums.org/2014/04/07 /library-partnership-subsidies-lps/. $\boldsymbol{n}$

4. M. A. Hubbard and A. T. Loos, "Academic library participation in recruitment and retention initiatives," Reference Services Review 41 (2):157-81.

5. L. Miller, "The library and the campus visit, Communicating value to prospective students and parents," College and Research Libraries News 73 (10):586-89.

6. M. G. Kopp, "Academic libraries, institutional missions, and new student recruitment: A case study," Reference Services Review 41 (2):192-200. $n$ 